\title{
Justiça ambiental e legitimação de direitos: \\ o mineroduto Ferrous Resources no município de Viçosa/MG pela perspectiva do conflito ambiental entre mineradora e atingidos
}

Environmental justice and legitimacy of rights: the pipeline to transport ore company Ferrous Resources

in Viçosa. Minas Gerais, Brazil, by the prospect of environmental conflict between mining and and communities affected by the project

\author{
Pollyana Martins Santos* \\ Marcelo Leles Romarco de Oliveira**
}

\section{Resumo}

O presente trabalho propõe uma abordagem teórica a respeito da temática dos conflitos ambientais pela perspectiva da distribuição de poder, nos campos material e simbólico, entre atores sociais envolvidos na disputa pelo acesso e domínio do território e de seus recursos naturais. Assim, tomando como objeto de análise o conflito de interesses havido entre diferentes segmentos sociais locais e a mineradora Ferrous Resources do Brasil, em decorrência da passagem de um mineroduto da empresa no município de Viçosa/MG, no âmbito do Inquérito Civil MPMG 0713.12.000149-8 do Ministério Público do Estado de Minas Gerais, o estudo procura descrever e analisar o conflito ambiental ali identificado, buscando investigar a possível ocorrência de injustiças ambientais no processo de implantação do mineroduto pretendido. Ao final, conclui-se que a dinâmica do conflito ambiental em questão aponta para uma situação de

Bacharel em Direito e Doutoranda em Economia Doméstica pela Universidade Federal de Viçosa. Viçosa - MG - Brasil. E-mail: pollyana.santos@ufv.br.

* Doutor em Ciências Sociais pela Universidade Federal Rural do Rio de Janeiro e Professor Adjunto III da Universidade Federal de Viçosa. Viçosa - MG - Brasil. E-mail: marcelo.romarco@ ufv.br. 
injustiça ambiental e evidencia as contradições do modelo de desenvolvimento capitalista, contribuindo para o debate a respeito das escolhas do chamado "desenvolvimento".

Palavras-chave: Conflito ambiental. Justiça ambiental. Assessoria.

\section{Abstract}

This paper proposes a theoretical approach of the theme of environmental conflicts from the perspective of the distribution of power, material and symbolic fields, between the social actors involved in the dispute for access and mastery of the territory and its natural resources. So, taking as object of analysis, the conflict of interest there between different local social sectors and the mining company Ferrous Resources of Brazil due to the passage of a pipeline in the municipality of Viçosa/MG, in the investigation of Civil Public Inquiry MPMG 0713.12.000149-8 of the Minas Gerais State Public Ministry, this study seeks to describe and analyze this environmental conflict, investigating the possible occurrence of environmental injustices in the deployment process of the intended pipeline route. Finally, it is concluded that the dynamics of environmental conflict points to a situation of environmental injustice, and highlights the contradictions of the capitalist development model, contributing to the debate about the choices of so-called "development".

Keywords: Environmental conflict. Environmental justice. Advice.

\section{Introdução}

O presente trabalho propõe uma abordagem teórica a respeito da temática dos conflitos ambientais pela perspectiva da distribuição de poder, nos campos material e simbólico, entre atores sociais envolvidos na disputa pelo acesso e domínio do território e de seus recursos naturais.

Neste sentido, o objeto de estudos escolhido foi o conflito de interesses entre diferentes segmentos sociais do município de Viçosa/ MG e a mineradora Ferrous Resources, em decorrência da possibilidade de passagem de um mineroduto da empresa na mencionada cidade, o 
que ensejou a instauração, pelo Ministério Público Estadual, do Inquérito Civil MPMG n 0713.12.000149-8.

Desta forma, o presente estudo tem como objetivo descrever e analisar o conflito ambiental trazido à apreciação do órgão público com a atribuição de defesa do meio ambiente, envolvendo a empresa proponente, as populações potencialmente impactadas pelo empreendimento e organizações de assessoria, buscando investigar a possível ocorrência de injustiças ambientais no processo de implantação do mineroduto pretendido.

\section{Da dinâmica do conflito ambiental}

Estudar a questão dos conflitos ambientais pressupõe, de início, aceitar a ideia de que meio ambiente e sociedade são duas realidades indissociáveis. Isto ocorre porque os elementos constitutivos do ambiente - tais como os recursos hídricos, os biomas florestais, o solo ou os recursos minerais - detêm significados simbólicos, culturais e históricos que influenciam diretamente a forma como os diversos segmentos sociais os encaram e deles se utilizam.

Isto equivale a dizer que um mesmo recurso natural será percebido diferentemente por cada ator social. Assim, o olhar e o agir de uma comunidade de pescadores e de uma empresa concessionária de energia sobre um mesmo rio, por exemplo, jamais serão os mesmos. Os interesses são os mais variados possíveis: a comunidade encara o rio como fonte de vida e, até mesmo, como marco simbólico de sua permanência naquela região. Já a empresa vê o rio como uma oportunidade de produção de energia.

Situações como a descrita acima se repetem ao longo do tempo e acabam por caracterizar a existência e evolução das próprias sociedades nas quais eclodem. Conflitos ambientais consistem, assim, em processos de disputa pelo acesso e domínio dos recursos ambientais. É neste sentido que Acselrad aponta que os processos de reprodução das sociedades são necessariamente caracterizados pelo confronto entre 
diferentes projetos de uso e significação de seus recursos ambientais, razão pela qual, conforme o autor, "a questão ambiental é intrinsecamente conflitiva, embora esse caráter nem sempre seja reconhecido no debate público" (ACSERALD, 2004a, p. 8).

Dando relevo a esta questão, o mesmo autor ressalta que "os conflitos ambientais deveriam ser analisados, portanto, simultaneamente nos espaços de apropriação material e simbólica dos recursos do território" (ACSERALD, 2004a, p. 23). Isto porque, conforme Oliveira (2004, p. 98), o campo ambiental é também um campo social de diferenciações, no qual são travadas lutas de poder e lutas simbólicas, no bojo das quais os agentes se esforçam para manter ou transformar a estrutura das relações ali existentes, legitimando ou deslegitimando práticas sociais ou culturais.

A dinâmica do conflito ambiental envolve, desta forma, a relação entre os dois espaços de manifestação do poder: o espaço material, no qual se observa a capacidade de acesso dos diferentes segmentos sociais aos recursos naturais territorializados, como a água, o solo, as formações vegetais, etc., o que se pode chamar de capital material ${ }^{1}$ como também de espaço de distribuição do poder; e o espaço simbólico, palco em que se confrontam as diferentes representações e valores de um determinado grupo social, isto é, o espaço da luta discursiva. É nesse último que se travam as lutas para a legitimação dos modos de distribuição de poder que se concretizam no espaço material.

Para Oliveira (2004, p.103), no campo simbólico, a probabilidade de prevalência do discurso é tanto maior quanto mais próximos estão os sujeitos políticos do lugar em que os instrumentos simbólicos são gerados, ou seja: a posição privilegiada é de quem é detentor do discurso autorizado. Em outras palavras: o sentido adquirido pela categoria "sustentabilidade" (termo tão recorrente nos dias de hoje), por exemplo, será alcançado através de lutas simbólicas, emergindo delas o conceito

A esse respeito, consultar Acselrad (2004a), "As práticas espaciais e o campo dos conflitos ambientais". 
que se amolda aos segmentos sociais melhor posicionados, de tal forma que este sentido de "sustentabilidade" é que legitimará o uso que estes mesmos grupos fazem do capital material. Isto leva à conclusão de que as "categorias de legitimação", portanto, são variáveis no tempo e no espaço, a depender das estruturas de poder vigentes.

Não por outra razão, Acserald (2004a, p.19) conclui que os espaços de conflito pelos quais se distribuem os atores sociais em sua disputa de poder são demarcados pela própria ação dos agentes sociais que ali se confrontam, uma vez que tais campos de confronto "não são constituídos, consequentemente, por lugares vazios, pois há neles ação e história produzidos pela ação coletiva". A partir destas considerações, o autor observa especificamente no que toca à temática ambiental que:

Deste ponto de vista, se considerarmos o meio ambiente como um terreno contestado material e simbolicamente, sua nomeação - ou seja, a designação daquilo que é ou não é ambientalmente benigno - redistribuiu o poder sobre os recursos territorializados, pela legitimação/deslegitimação das práticas de apropriação da base material das sociedades e/ou de suas localizações. As lutas por recursos ambientais são, assim, lutas por sentidos culturais. Pois o meio ambiente é uma construção variável no tempo e no espaço, um recurso argumentativo a que atores sociais recorrem discursivamente através de estratégias de localização conceitual nas condições específicas da luta social por 'mudança ambiental', ou seja, pela afirmação de certos projetos em contextos de desigualdade sociopolítica (ACSERALD, 2004a, p. 19, grifo nosso).

Desta feita, se, de acordo com Castells (1999, p. 53) "cada modo de desenvolvimento é definido pelo elemento fundamental à promoção da produtividade no processo produtivo", é interessante notar a relação feita por Acselrad (2004a, p.16-17) entre conflitos ambientais e modelos de desenvolvimento. Segundo este autor, cada modelo de desenvolvimento tende a acarretar um tipo específico de conflito, decorrente das contradições do próprio modelo. 
É assim que, no Brasil, cujos projetos de desenvolvimento econômico foram marcados por calamitosas consequências sociais, culturais e ambientais, o antagonismo entre meio ambiente e desenvolvimento marcou o solo do debate ambiental nas décadas de 1970 e 1980. Para Zhouri e Laschefski (2010), as discussões promovidas pelo movimento seringueiro na Amazônia brasileira, que traziam para o debate o binômio manutenção da floresta e direito das populações tradicionais que ocupavam esses territórios, assim como a morte de Chico Mendes em 1988, foram marcos da luta entre ambientalistas e desenvolvimentistas, o que trouxe reflexões importantes para pensarmos a relação entre desenvolvimento, meio ambiente e natureza.

É neste contexto que, principalmente a partir da década de 1990, situações emblemáticas de conflitos ambientais são então consagradas como simples "problemas" ou "impasses" a serem resolvidos por meio das técnicas de conciliação, reduzindo-se ou desconsiderando-se todo o campo de valores que permeia a disputa material em questão. Desta feita, são apontadas como restrições ambientais ao desenvolvimento quaisquer outras iniciativas que procurem encarar estes conflitos como expressões de diferenças simbólicas entre atores sociais.

A partir dessa lógica, é possível compreender como empresas proponentes de empreendimentos ambientalmente impactantes podem tecnicamente cumprir com todas as formalidades determinadas pela legislação ambiental (por exemplo, a realização de estudos ambientais obrigatórios) mantendo inalterada, contudo, a sua lógica norteadora de apropriação capitalista dos recursos naturais (ACSERALD, 2004a, p. 21-23).

A esse respeito, Vargas (2007, p. 198) aponta que os conflitos ambientais têm sido cada vez mais constantes nos países da América Latina. Para a autora, isso se deveria "em parte em consequência da debilidade na implementação das políticas e esquemas de gestão disponíveis para a regulação do uso e acesso dos recursos naturais". Por esta razão, Vargas destaca a importância de considerar a complexidade das dinâmicas culturais, sociais e econômicas que envolvem a natureza, 
procurando identificar os atores sociais envolvidos nesses conflitos e seus interesses e relações com o meio ambiente.

Essas reflexões apontam, assim, para a compreensão de que o meio ambiente deve ser encarado como um terreno contestável material e simbolicamente, o que consiste em reconhecer, na verdade, que os conflitos ambientais se traduzem em relações de poder, através das quais os atores sociais, munidos de suas distintas formas de interagir com o ambiente, se enfrentam pelo domínio de um mesmo território ou de seus recursos naturais. Acselrad (2004a, p. 26) definiu os conflitos ambientais como:

Aqueles envolvendo grupos sociais com modos diferenciados de apropriação, uso e significado do território, tendo origem quando pelo menos um dos grupos tem a continuidade das formas sociais de apropriação do meio que desenvolvem ameaçada por impactos indesejáveis - transmitidos pelo solo, água, ar ou sistemas vivos - decorrentes do exercício das práticas de outros grupos.

Nesta mesma linha de raciocínio, Andrade et al. (2007) constatam que os conflitos ambientais podem ser classificados como um tipo de conflito social relacionado com a disputa de grupos pelo controle de um determinado recurso ambiental. Portanto, essa realidade se configuraria por um espaço designado pelo choque de interesses entre indivíduos e grupos, tendo como um dos objetivos a apropriação privada dos recursos naturais.

Nessa esteira, autores como Alonso e Costa (2002) adotam como premissa que os conflitos ambientais mobilizam uma grande quantidade de atores e se apresentam com uma série de divisões, que podem ser sociais, políticas, culturais e econômicas, as quais podem variar em função da natureza do problema ou do recurso envolvido na disputa. Desta forma, os autores propõem que é necessário considerar o conjunto de aspectos estruturais, grupais e individuais que condicionam a ação e jogo de alianças que são formados entre os agentes envolvidos no conflito. 
Enriquecendo este debate, o antropólogo Paul Little (2001) propõe uma classificação dos conflitos ambientais por três perspectivas, quais sejam: a) aqueles relacionados com o controle e a disputa sobre os recursos naturais, como o uso dos recursos florestais; b) os conflitos que estão relacionados com os impactos socioambientais provocados pela ação humana sobre a natureza, ou seja, como a construção de barragens para a geração de energia hidroelétrica; e, c) os conflitos que envolvem elementos culturais e impactam os modos de vidas das populações envolvidas, ou seja, o embate de valores ou ideologias. Compreender essa tipologia dos conflitos ambientais pode contribuir para entendê-los em sua essência e, até mesmo, mitigá-los.

Neste sentido, Little (2001) chama atenção para a necessidade de adotar, como primeiro passo na abordagem dos conflitos ambientais, o entendimento do que se encontra em jogo, levando em consideração as diversas dimensões que podem estar envolvidas no conflito, assim como buscar mapear os principais atores sociais participantes. Na visão do autor, isso permitirá apontar os interesses de cada parte no conflito, as dimensões de poder material e simbólico que permeiam a disputa, assim como as variáveis culturais que orientam o agir e pensar dos atores sociais envolvidos no jogo do conflito ambiental.

Esse contexto nos permite compreender, portanto, que lutas ambientais consistem, em última instância, em lutas por sentidos culturais, simbólicos e materiais, o que vem se sobrepor ao paradigma a que Zhouri, Laschefski e Paiva (2005, p. 12) conceituaram como "política de gestão", na qual a natureza é tida como uma realidade externa ao processo produtivo que deve ser manejada e gerida de forma a não se tornar um óbice ao dito "desenvolvimento". A política de gestão é assim pautada por uma persistente lógica de adequação ambiental, por meio da qual a natureza e o ambiente são, em verdade, adaptados a empreendimentos representativos de significativos interesses econômicos sob o argumento de atendimento ao interesse público.

Esse fato traz intrínseca outra importante constatação: a de que são historicamente assimétricas estas relações de poder (ZHOURI; 
ZUCARELLI, 2008, p. 04), o que faz com que os conflitos ganhem um caráter de disputa injusta. Isto porque os instrumentos e os recursos de que dispõem os atores sociais envolvidos na demanda, via de regra, são muito desiguais, com a balança pendendo quase sempre em favor daqueles econômica e politicamente mais poderosos.

Esta situação reflete, portanto, um processo de monopolização dos recursos naturais por parte dos grupos sociais dominantes, que têm a seu dispor todo um poderio político-econômico para impor os seus interesses em detrimento de outras práticas que reflitam os modos de apropriação do ambiente por grupos sociais mais vulneráveis.

Este processo é apontado por Acserald, Herculano e Pádua (2004b, p. 09-10) como um quadro tipicamente marcado por uma situação de injustiça ambiental, entendida por estes autores como sendo um mecanismo sociopolítico característico das sociedades marcadas pela desigualdade, o que faz com que os segmentos sociais mais vulneráveis arquem com a maior parte das consequências dos danos ambientais provenientes do chamado desenvolvimento.

O quadro supramencionado se descortina no âmbito de projetos ambientalmente impactantes (como barragens hidrelétricas, mineração, linhas de transmissão, dutos para condução de gás, óleo, minério, dentre outros), nos quais o interesse econômico na construção do empreendimento se sobrepõe aos interesses de outras populações que tradicionalmente ocupam o território e usufruem dos respectivos recursos naturais requisitados para a obra. Isto porque, à medida que os empreendedores têm seu interesse legitimado face ao modelo de mercado que reduz desenvolvimento ao crescimento econômico, as populações afetadas carecem de instrumentos que as tornem capazes de confrontarem em pé de igualdade o empreendedor. Logo, o que acaba ocorrendo com tais grupos sociais é a desqualificação da condição de verdadeiros sujeitos na relação para meros expectadores no processo de apropriação de espaços (ZHOURI; LASCHEFSKI; PAIVA, 2005, p.89). 
É dentro deste cenário que Zhouri e Rothman (2008, p. 122) destacam a importância de organizações sociais que, a partir de suas percepções simbólicas a respeito das injustiças ambientais que caracterizam a implantação de tais empreendimentos, se encontram estruturadas com a finalidade de prestar apoio a estes segmentos mais vulneráveis, buscando equilibrar a relação de conflito e, assim, diminuir as desigualdades de poder no campo material. A esse respeito, assevera Acserald (2004b, p. 29):

Essa ação coletiva, quando dirigida contra a ordem ambiental tida por injusta manifesta-se simultaneamente em dois planos: a) no plano da distribuição objetiva dos efeitos ambientais das práticas sociais; esta distribuição exprime a diferença de poder sobre os recursos ambientais entre os distintos grupos sociais, e b) no plano discursivo, onde vigoram distintos esquemas de representação do mundo, do ambiente, da justiça, etc; neste plano, coloca-se em jogo a legitimidade do modo de distribuição do poder sobre os recursos ambientais [...]. Os movimentos sociais podem ser analisados por sua intervenção nestes dois níveis do espaço social - o espaço da distribuição do poder sobre as coisas e o espaço da luta discursiva.

Logo, tais organizações atuam como agentes de capacitação e empoderamento das comunidades ameaçadas, contribuindo, em última instância, para o combate das injustiças ambientais que caracterizam a implantação dos projetos questionados. Logo, podem consistir em canal para que o afloramento dos conflitos ambientais tenha como resultado legitimação de direitos e justiça ambiental.

Contudo, o empoderamento de populações vulneráveis por meio da assessoria prestada por tais grupos pode redundar no deslocamento do conflito ambiental para outras áreas em que o estabelecimento de resistências e a mobilização social dos atingidos sejam mais incipientes ou mesmo ausentes. Tal ocorre porque, num sistema econômico capitalista, o capital tende a abandonar áreas de maior organização política e se concentrar em áreas mais fragilizadas, de menor capacidade de organização e resistência social, conforme alerta Acserald (2004b, p. 
32). Neste contexto, este pode ser um dos maiores desafios enfrentados por organizações de luta por equidade ambiental, a fim de se evitar que as injustiças ambientais não sejam exportadas, em decorrência da mobilidade do capital, para outras zonas ainda carentes de organização.

\section{A passagem do mineroduto Ferrous Resources no município de Viçosa/MG e a instauração do Inquérito Civil MPMG 0713.12.000149-8}

A Ferrous Resources do Brasil é uma mineradora brasileira criada em 2007, que atualmente possui 3 (três) minas no Quadrilátero Ferrífero mineiro. Com uma produção média estimada em 5 milhões de toneladas de minério de ferro ao $\mathrm{ano}^{2}$, um dos investimentos da empresa é a criação de um mineroduto para escoamento de sua produção minerária, desde a mina no município de Congonhas/MG até o porto em Presidente Kennedy/ES, de onde o minério de ferro partirá para exportação. Em seu traçado, o mineroduto pretendido pela Ferrous passará por três Estados brasileiros (Minas Gerais, Rio de Janeiro e Espírito Santo) atravessando 22 municípios, dentre eles Viçosa/MG ${ }^{3}$.

Nesta esteira, no dia 10 de maio de 2012, representantes de diferentes segmentos sociais, a saber: Projeto de Assistência às Comunidades Atingidas por Barragens (PACAB) ${ }^{4}$, Movimento dos Atingidos por Barragens (MAB), Comunidades do bairro Santa Clara e da zona rural Palmital, e movimentos estudantis da UFV, compareceram à $2^{a}$ Promotoria de Justiça da Comarca de Viçosa, onde levaram ao

2 Informações obtidas no site da empresa, disponíveis em: <https://www.ferrous.com.br/index.php/ pagina/view/11/11>. Acesso em: 19 nov. 2014.

3 Considerando que o empreendimento pretendido pela empresa Ferrous abrangerá o território de 03 estados brasileiros, a competência para o licenciamento ambiental da obra é federal, a cargo do IBAMA - Instituto Brasileiro do Meio Ambiente e dos Recursos Naturais Renováveis, a teor do que dispõe a Lei Complementar n ${ }^{0}$ 140, de 08 de dezembro de 2011.

4 O Projeto de Assessoramento as Comunidades Atingidas por Barragens e Mineração (PACAB) é um grupo de Extensão e Pesquisa que tem 18 anos de assessoramento a comunidades atingidas por empreendimentos. O grupo é formado por professores e estudantes da Universidade Federal de Viçosa (UFV), na região da Zona da Mata de Minas Gerais. 
conhecimento do Promotor de Justiça Curador do Meio Ambiente a preocupação com os impactos ambientais a serem causados pela construção do mineroduto, especialmente no que toca ao abastecimento de água do município, historicamente já bastante fragilizado. $\mathrm{Na}$ oportunidade, foi apresentado pelos representantes dos movimentos sociais um "dossiê" contendo várias informações e denúncias a respeito do empreendimento, conforme síntese contida na ata da reunião realizada na ocasião:

Aberta a reunião, foram trazidas ao Ministério Público informações relativas ao mineroduto Ferrous Resources, em especial relativas à degradação ambiental que se levará a efeito tão logo iniciada a sua execução. Frisouse os reflexos no abastecimento de água da cidade, cujos mananciais que lhe dão suporte já se encontram no limite, conforme, inclusive, documentado pela companhia de abastecimento de água, e que justificaria a escassez de água em vários pontos da cidade durante o período de estiagem. [...] Pontuaram-se as inúmeras implicações com a execução do mineroduto no município de Viçosa, sendo destacadas: a) a instalação da estrutura no local por onde perpassará o mineroduto; b) o risco imediato de assoreamento dos mananciais, em razão da terra que será removida para passagem do mineroduto e da proximidade entre ele e o curso d'água; c) o risco de contaminação do solo e da água pelo óleo lançado pela grande quantidade de máquinas utilizadas na empreitada; d) o impacto e também possibilidade de assoreamento proveniente dos inúmeros bota- foras instalados nas proximidades do ribeirão São Bartolomeu, e para os quais será removida a terra; e) a possibilidade de contaminação da água e do solo com metais pesados; f) o risco do rompimento do mineroduto, que, por passar em inúmeros mananciais, tal como recentemente ocorreu no município de Espera Feliz. Ademais, foi informada absoluta omissão do Poder Público local e até mesmo desconhecimento em relação aos impactos que a obra causará ao município, sendo certo que o próprio Chefe do Poder Executivo anunciou em rádio que o mineroduto é inegociável; que o Secretário 
de Meio Ambiente desconhece o trajeto do mineroduto e, por conseguinte, as conseqüências da empreitada, tendo firmado que 'daria a cara para cuspir' caso a obra atingisse ou passasse por alguma nascente. Por fim, foi colocada a preocupação quanto aos aspectos sociais relacionados com essa grande obra, pelas suas conseqüências no incremento da criminalidade, da drogadição e prostituição. (INQUÉRITO CIVIL MPMG n 0713.12.000149-8, 2012, p. 03).

Com cerca de 5 (cinco) localidades rurais no município de Viçosa diretamente impactadas pelo mineroduto, sendo elas: Palmital, Machado, Juquinha de Paula, Vila Nova Paraíso e Córrego do Engenho (todas inseridas na região de afluência do ribeirão São Bartolomeu, um dos principais mananciais do município), a organização destes diferentes segmentos civis deu origem ao movimento denominado "Campanha pelas Águas de Viçosa e contra o Mineroduto", já tendo sido realizadas antes do comparecimento no Ministério Público diversas assembleias populares, existindo inclusive posicionamento formal da Câmara de Vereadores de Viçosa contra o empreendimento ${ }^{5}$.

A mobilização dos segmentos sociais mencionados ensejou a instauração, pelo Ministério Público, do Inquérito Civil MPMG nº 0713.12.000149-8 . Contudo, muito embora os representantes tenham trazido a informação de que violações de direitos humanos também estavam sendo cometidas pela empresa representada no decorrer das negociações fundiárias, já que, segundo o dossiê, a empreendedora "chega de maneira arbitrária nas comunidades, abusando de seu poder e intimidando os proprietários, alegando que eles não têm escolha, que o mineroduto vai passar de qualquer maneira queiram ou não queiram" (INQUÉRITO CIVIL MPMG no 0713.12.000149-8, p. 14), esta demanda

NACAB, 2012, p. 206.

6 O Inquérito Civil consiste em um procedimento administrativo no âmbito do Ministério Público, com finalidade inquisitiva e investigativa. Tem como objetivo cotejar elementos de convicção para a atuação processual do Promotor de Justiça, geralmente a propositura de uma Ação Civil Pública em defesa dos direitos difusos e coletivos, como meio ambiente, consumidor, patrimônio histórico e cultural, dentre outros. Sua fundamentação legal está na Lei 7.347, de 24 de julho de 1985. 
específica foi entendida como sendo de cunho unicamente social por parte da $2^{a}$ Promotoria de Justiça. Por esta razão, foram remetidas cópias de todos os documentos à $4^{a}$ Promotoria de Justiça de Viçosa, esta com atribuição para a curatela dos Direitos Humanos, remanescendo para análise do Inquérito Civil MPMG n 0713.12.000149-8 tão somente as implicações do empreendimento tidas como ambientais.

A nosso ver, embora se trate de uma divisão administrativa interna de atribuições do Ministério Público estadual, é interessante registrar que tal postura não coaduna com entendimento teórico defendido por Acserald (2004), segundo o qual social e ambiental são dois conceitos indissociáveis, de tal maneira que o ambiental já traz ínsito em si a noção do social. Neste sentido, a repartição dos objetos do Inquérito Civil mencionado revela, no âmbito do órgão público, uma dicotomia expressa entre o que seriam, de um lado, "conflitos ambientais", e, por outro, "conflitos sociais", o que poderia vir a ser um limitador para a análise das implicações do empreendimento em toda sua amplitude.

É possível observar no Inquérito Civil um forte confronto entre os atores sociais envolvidos na implantação do mineroduto, quais sejam: a empresa proponente e as populações impactadas pelo empreendimento. Resta evidenciado o conflito de interesses na apropriação do território, característico do conflito ambiental, tal como apontado por Acserald (2004a). Isto porque, diante da ameaça por parte da atividade pretendida pela empresa mineradora de comprometimento do acesso da população local ao território e, principalmente, ao recurso natural "água", estabeleceu-se o conflito entre duas racionalidades distintas, exsurgindo como uma das arenas de disputa o procedimento administrativo formalmente instaurado no âmbito de um órgão público no caso, o Inquérito Civil MPMG 0713.12.000149-8 do Ministério Público do Estado de Minas Gerais.

É neste sentido que, contrapondo-se diretamente ao discurso dos representantes das populações atingidas, a empresa Ferrous apresenta, às páginas 25 a 40 e 84 a 137 dos autos do referido Inquérito Civil, documentação na qual procura demonstrar o cumprimento de 
todas as medidas necessárias a assegurar a viabilidade sócio-ambiental do mineroduto pretendido. Sendo assim, em sua argumentação, a mineradora relata que todos os impactos ambientais estão previstos no $\mathrm{EIA}^{7}$ e foram objeto de discussão nas reuniões prévias e audiências públicas, tendo sido previstas medidas de controle, mitigação e monitoramento no Plano Básico Ambiental por ela apresentado ao IBAMA por ocasião do licenciamento ambiental da obra. A esse respeito salienta a empreendedora que:

Vem atendendo rigorosamente as normas ambientais aplicáveis, assim como todas as condicionantes e solicitações colocadas pelo órgão ambiental, inclusive investindo em programas sociais que objetivam o desenvolvimento das comunidades localizadas no entorno (INQUÉRITO CIVIL MPMG no 0713.12.000149-8, 2012, p. 86).

A partir destas considerações, observa-se que uma das preocupações da Ferrous é o de destacar a existência de um bom relacionamento com as populações locais, rebatendo, desta maneira, a afirmação de que as comunidades eventualmente impactadas estariam insatisfeitas com a condução das negociações por ela empreendidas. Neste sentido, frisa a empresa que "possui 17 agentes sociais ao longo do mineroduto - pessoas moradoras dos municípios e responsáveis por manter o diálogo e o relacionamento próximo com todos os proprietários de terra" (INQUÉRITO CIVIL MPMG no 0713.12.000149-8, 2012, p. 32).

Merece destaque a afirmativa de que os agentes sociais selecionados pela empresa foram escolhidos dentre os próprios moradores das localidades impactadas pelo empreendimento. Isto porque, embora tal medida tenha sido justificada como forma de se

7 O EIA, Estudo de Impacto Ambiental, é um documento técnico no qual se procuram avaliar as consequências ambientais da instalação de determinado empreendimento. Deve ser apresentado pelo empreendedor ao órgão ambiental responsável por conduzir o licenciamento ambiental do empreendimento. No caso do mineroduto da empresa Ferrous, o licenciamento ambiental é de responsabilidade do Instituto Brasileiro do Meio Ambiente e dos Recursos Naturais Renováveis (IBAMA). 
promover a aproximação entre a empresa e atingidos, a iniciativa pode sinalizar a estratégia apontada por autores como Zhouri e Rothman (2008, p. 43), segundo os quais é uma prática comum que as empresas interessadas na construção de empreendimentos ambientalmente impactantes façam a cooptação de lideranças ou indivíduos-chave entre as comunidades atingidas como meio de facilitar a aceitação e implantação de seus projetos pelas populações afetadas.

Outro ponto destacado pela mineradora é que seu empreendimento é legal e conta com apoio do Poder Público, já que o mesmo foi declarado como sendo de utilidade pública por meio de Decreto do Governador do Estado de Minas Gerais ${ }^{8}$. Desta forma, nas áreas onde restou frustrada a negociação entre moradores e empresa, possibilitou-se a imposição judicial de institutos como a servidão administrativa ${ }^{9}$, viabilizando legalmente a construção do empreendimento independentemente da anuência do proprietário das terras. A esse respeito, esclarece a empresa que:

Nas hipóteses em que, apesar das tentativas de negociação, não seja possível chegar a um acordo consensual (sic), é facultado à FERROUS encaminhar tais casos aos cuidados da Companhia de Desenvolvimento Industrial de Minas Gerais - CODEMIG, que, valendo-se das disposições do Decreto de Utilidade Pública de 20 de maio de 2010, pode ajuizar ações de desapropriação, instituição de servidão administrativa e ocupação temporária que possuem como objeto o acesso aos terrenos necessários à construção do Mineroduto da Ferrous. Entretanto, apesar de necessário em algumas ações, levar a questão do acesso à terra à via judicial não é prioridade da empresa. (INQUÉRITO CIVIL MPMG no 0713.12.000149-8, p. 112).

8 O mineroduto pretendido pela empresa Ferrous foi favorecido com o Decreto de Utilidade Pública em 20 de maio de 2010, conforme publicação do Diário Oficial do Estado de Minas Gerais (DOEMG) em 21 de maio de 2010.

9 A servidão administrativa consiste em "direito real de gozo, de natureza pública, instituído sobre imóvel de propriedade alheia, com base em lei, por entidade pública ou por seus delegados, em face de um serviço público ou de um bem afetado a fim de utilidade pública" (DI PIETRO, 2008). Em termos práticos, isto significa que independe da vontade do proprietário a passagem do empreendimento por suas terras, fazendo ele jus à indenização. 
Percebe-se, dessa maneira, como o discurso da empresa revela a sua preocupação em evidenciar a legitimidade do projeto, reafirmando sua sustentabilidade e respaldo legal. Desta forma, a declaração de utilidade pública conferida ao mineroduto pode demonstrar a prevalência do capital simbólico da empresa, enquanto detentora do discurso autorizado (OLIVEIRA, 2004), em face de um modelo político-econômico que prioriza a instalação de tais empreendimentos como indispensáveis ao desenvolvimento do país - principalmente se considerarmos a informação trazida pela Associação dos Geógrafos do Brasil (2012, p.152) de que a declaração de utilidade pública precedeu em mais de 1 ano a própria concessão da Licença Prévia ${ }^{10}$ do empreendimento (esta última obtida em 22 de junho de 2011, enquanto o Decreto de Utilidade Pública foi conferido em 20 de maio de 2010).

De outro lado, como subsidiários aos discursos, tanto da empresa proponente quanto dos representantes dos atingidos, constam ainda nos autos do procedimento relatórios técnicos a respeito das implicações do mineroduto. Um deles consiste no Laudo Técnico da Central de Apoio Técnico do Ministério Público (CEAT), realizado por requisição da $2^{a}$ Promotoria de Justiça. Em linhas gerais, o documento, acostado às páginas 56 a 73 dos autos do Inquérito Civil MPMG n 0713.12.000149-8, aponta fragilidades nos estudos ambientais apresentados pela Ferrous, notadamente quanto à identificação dos mananciais de abastecimento da cidade de Viçosa, o que, conforme aponta o Perito responsável:

Demonstra inconsistência do EIA em relação ao cadastramento de usos de água a jusante das travessias ao longo de todo o mineroduto. Ou seja, as informações de que o consumo humano de $5,5 \%$ dos usos cadastrados, um percentual relativamente baixo... e de que outros $75,26 \%$ dos usos cadastrados se destinam à dessedentação animal apresentados pelo empreendedor, não correspondem à

10 A Licença Prévia é concedida na fase preliminar do procedimento de licenciamento ambiental da obra. Atesta a viabilidade ambiental do projeto, embora não autorize o início das obras. 
realidade dos usos das águas verificados no âmbito do município viçosense [...]. O mapeamento de nascentes, travessias e usos RTC 08 do EIA não relata, por exemplo, que parte do traçado do mineroduto está projetado sobre o leito dos cursos d'água e que, por isso, as obras podem sim, ter maior duração e, o que é pior, podem ocasionar danos ambientais e risco de desabastecimento de água para o consumo humano e para os trabalhos de pesquisa na UFV, dentre outros usos não contemplados no diagnóstico ambiental (CEAT, 2012, p. 60-62).

Neste mesmo sentido, o Parecer Técnico requisitado pelo Ministério Público ao Serviço Autônomo de Água e Esgoto do município de Viçosa (SAAE), autarquia responsável pelo abastecimento público de água na cidade, acostado às páginas. 80 a83 do mencionado Inquérito Civil, reafirma que os mananciais do município já se encontram em seu limite de abastecimento, demonstrando forte preocupação com as consequências que a construção do mineroduto poderá causar em um sistema já bastante fragilizado. A esse respeito, atesta a equipe técnica que:

O empreendimento causará impactos diretos no ribeirão São Bartolomeu e no rio Turvo Sujo, em algumas nascentes e em vários trechos desses cursos d'água, inclusive no local onde está prevista a captação de água para atender a futura ETA III. (SAAE, 2012, p. 81-82).

Diante das manifestações até então colacionadas aos autos, foi realizada, por iniciativa do Ministério Público, no dia 12 de julho de 2012, Audiência Pública buscando publicizar as discussões a respeito das implicações da construção do mineroduto no município de Viçosa e ouvir diretamente a população afetada pelo empreendimento. O evento, realizado na escola Almiro Paraíso, na localidade rural de Paraíso/Viçosa (uma das comunidades rurais diretamente impactadas), intitulado "Água ou Minério? Impactos Sociais e Ambientais na Construção do Mineroduto Ferrous Resources", contou com a participação de Promotores de 
Justiça da $2^{\mathrm{a}}$ e da $4^{\mathrm{a}}$ Promotorias de Justiça de Viçosa, da CIMOS ${ }^{11}$, do $\mathrm{CAOMA}^{12}$ e do Ministério Público Federal (MPF), além de Defensores Públicos da Comarca de Viçosa. Na oportunidade, vários membros das comunidades relataram preocupação com o empreendimento e colocaram-se contrários à construção do mineroduto, com denúncias principalmente de arbitrariedades na condução das negociações fundiárias conduzidas pela empresa. Por sua vez, representantes da comunidade acadêmica ligados à Universidade Federal de Viçosa (UFV) apontaram estudos por eles realizados que atestavam falhas e inconsistências nos estudos ambientais trazidos pela Ferrous (INQUÉRITO CIVIL MPMG no 0713.12.000149-8, 2012, p. 75-78).

A esse respeito, é importante mencionar que restou caracterizada a construção de uma nítida relação entre a população afetada pelo empreendimento, organizações civis e acadêmicos vinculados à UFV. A própria inciativa de provocar a atuação Ministerial contou com a participação do representante do Projeto de Extensão PACAB, prosseguindo a assessoria prestada por membros da Academia aos atingidos no curso do Inquérito Civil. Nota-se que a assessoria materializou-se principalmente no fornecimento de estudos técnicos a se contraporem àqueles trazidos pela mineradora, culminando com a capacitação e empoderamento dos atingidos pelo empreendimento, uma característica semelhante à dinâmica descrita nos estudos de Rothman (2008) e Zhouri e Rothman (2008) por ocasião da construção de resistências em decorrência da implantação de barragens hidrelétricas.

Neste sentido, três órgãos formados por profissionais vinculados à UFV apresentaram nos autos relatórios técnicos a respeito do mineroduto da empresa Ferrous Resources: a Associação dos Geógrafos Brasileiros - Seção Viçosa (AGB-Viçosa); o Núcleo de Assessoria às Comunidades

\footnotetext{
11 Coordenadoria de Inclusão e Mobilização Sociais do Ministério Público do Estado de Minas Gerais.

12 Central de Apoio Operacional das Promotorias de Justiça de Meio Ambiente do Ministério Público do Estado de Minas Gerais.
} 
Atingidas por Barragens ${ }^{13}$ (NACAB) e a Divisão de Água e Esgoto da UFV. Além da análise documental dos relatórios ambientais apresentados pela mineradora, as pesquisas foram subsidiadas pela realização de trabalho de campo, através de entrevistas com moradores atingidos e georreferenciamento das propriedades potencialmente afetadas e dos mananciais de abastecimento do município de Viçosa. Em todos os estudos, foram trazidos aos autos do Inquérito Civil elementos técnicos que contrariaram as informações oficiais apresentadas pela mineradora Ferrous no EIA por ela elaborado e apresentado ao IBAMA por ocasião do licenciamento ambiental da obra.

Inicialmente, o relatório trazido pela AGB-Viçosa ressalta, dentre outros aspectos, a insatisfação dos entrevistados com negociações fundiárias conduzidas pela empresa. Neste sentido, destaca o estudo que "as entrevistas apontam para a falta de informação sobre a questão jurídica e pressão psicológica sobre os moradores", principalmente dentre aqueles mais humildes e sem instrução formal (AGB, 2012, p. 157). Uma informação importante a esse respeito, identificada em estudo semelhante, foi trazida por Souza et al. (2013), que informam que, em 2011, num total de 06 comarcas potencialmente impactadas pelo mineroduto, somavam-se 337 ações judiciais questionando as indenizações propostas pela Ferrous, sendo que, deste total, um terço delas concentrava-se na comarca de Viçosa.

O relatório da AGB-Viçosa ainda aponta que foram excluídos das negociações indivíduos que não possuíam a propriedade formal das terras, como posseiros e meeiros. Desta feita, constataram os pesquisadores que:

Os trabalhadores meeiros, parceiros ou funcionários de outrem que vivem da terra e ou que necessitem do

13 Núcleo de Assessoria a Comunidades Atingidas por Barragens (NACAB), é uma ONG com atuação na Zona da Mata de MG, formada por ambientalistas ligados a UFV, atingidos por barragens e outros segmentos da sociedade organizada, que tem como princípio a defesa e o aprofundamento dos direitos individuais, sociais e difusos, como instrumento de reforço da solidariedade social. Informação constante na página da ONG, disponível em: <http://www. ongnacab.com.br>. Acesso em: 20 nov. 2014. 
trabalho na mesma para seus sustentos não terão direito a nenhum tipo de indenizações ou benefícios. Logo, serão afetados e não terão nenhum direito de contestação diante do projeto, uma vez que a empresa, a partir de uma visão patrimonialista de relações sociais, não os considera como atingidos. Foram constatados, no decorrer do trabalho de campo, diversos casos em que parceiros e meeiros não são considerados como atingidos, mesmo quando perdem, além de suas residências, a 'roça' (lavoura), perdendo assim, todo seu meio de reprodução social. (AGB, 2012, p. 157-158).

Desta feita, a desconsideração, por parte da empresa, das pessoas que não possuem o título de propriedade, , embora ligadas à terra, bem como o relato de tratamento diferenciado dispensado aos afetados pela obra (já que há informação no laudo da AGB de que os proprietários com melhor grau de formação ou maior capacidade econômica receberam melhor tratamento da empresa e foram beneficiados em detrimento daqueles em situação de vulnerabilidade), parece sinalizar para uma situação característica de injustiça ambiental, conforme apontado por Acselrad, Herculano e Pádua (2004) e Gould (2004).

Outro dado técnico constante dos documentos oficiais da empresa Ferrous que é contestado pelos estudos da AGB diz respeito aos mananciais impactados pelo mineroduto. A esse respeito, o georreferenciamento realizado pela associação aponta um número muito maior de nascentes afetadas do que aquele informado pela empreendedora:

Percebe-se que, segundo a empresa, na bacia do Ribeirão São Bartolomeu existem apenas 06 nascentes atingidas pelo mineroduto e na sub-bacia do Palmital apenas 02 nascentes mapeadas [...]. Isto tem implicações muito sérias, pois todos os impactos que foram esperados levando em consideração a intervenção em 06 nascentes estarão muito fora da realidade, visto que na verdade serão impactadas 30 nascentes na bacia do São Bartolomeu. Somando as nascentes mapeadas pela Ferrous e as que a AGB mapeou, o total é de 60 nascentes somente no município de Viçosa 
(AGB, 2012, p. 178).

Por sua vez, o relatório técnico apresentado pelo NACAB acompanha as conclusões do relatório da AGB, especialmente quanto à significativa discrepância de nascentes a serem impactadas pelo empreendimento. Uma das questões destacadas no documento é a contradição verificada no EIA da empresa Ferrous, no qual se afirma que no município de Viçosa não foram identificados pontos de consumo humano de água a jusante do mineroduto. Contudo, atestam os pesquisadores do NACAB que "foi feito um trabalho de campo e esta característica teria que ter sido identificada, uma vez que a bacia atingida é o manancial da cidade". Prosseguindo, os técnicos apontam que a informação trazida pela empresa "não confere com a realidade encontrada no levantamento realizado pela equipe de campo que aqui se pronuncia, pois neste verificaram-se diversos usos para o consumo humano, para a irrigação e para a dessedentação de animais" (NACAB, 2012, p. 214).

Concluindo a análise a respeito dos mananciais, a equipe técnica reforça que as incongruências por eles verificadas nos estudos da empresa Ferrous "possibilitam questionar a qualidade e ressaltar a incipiência do levantamento de nascentes feito no EIA", sendo certo que "o ElA elaborado é incapaz de prever os impactos referentes aos recursos hídricos, bem como planejar ações mitigadoras, uma vez que os estudos estejam equivocados, toda análise que foi feita o será também" (NACAB, 2012, p. 221).

Outro aspecto que se destacou no relatório do NACAB diz respeito aos valores de indenização estabelecidos pela empresa para aqueles casos nos quais houve a judicialização do conflito. O estudo apontou falhas na metodologia adotada pelo Perito contratado pela empresa Ferrous, sendo elas:

1. Laudo generalista e superficial, que não retrata a realidade local; 2. Coleta de dados de imóveis de áreas maiores e de regiões de áreas diferentes; 3 . Procedimento metodológico realizado de maneira equivocada; 4 . Erro no saneamento 
de dados; 5. Uso de apenas um fator de homogeneização (Índice Agronômico) para homogeneizar os dados e o uso do Fator Acesso de modo incorreto, e a inexistência do Uso de Fatores consagrados (Fator área, Fator Recurso Hídrico, Fator Transposição, dentre outros); 6. Inconsistência na obtenção do fator Índice Agronômico; 7. Desvalorização da área remanescente e do cálculo do lucro cessante feito de maneira incorreta. (NACAB, 2012, p. 234-235).

Para demonstrar as deficiências das avaliações judiciais levadas a cabo pela Ferrous, os técnicos do NACAB refizeram as análises em três propriedades rurais avaliadas pelo perito da empresa: Sítio São Jorge, Sítio Ventania e imóvel Ventania. Nos três casos, os valores alcançados pelo NACAB em muito superaram aqueles oferecidos pela Ferrous ${ }^{14}$, sendo a variação de cerca de $200 \%$ no primeiro imóvel, de $270 \%$ no segundo imóvel, e, no terceiro imóvel, de $350 \%$, ou seja, foram alcançados valores indenizatórios significativamente maiores que aqueles calculados pela empreendedora (NACAB, 2012, p. 230-277).

Importante ressaltar que, embora tais questões de trato fundiário não tenham sido objeto de apreciação do Inquérito Civil MPMG $n^{\circ}$ 0713.12.000149-8, as inconsistências encontradas sinalizam a fragilidade das análises realizadas pela mineradora, contribuem para o questionamento dos estudos por ela apresentados e, até mesmo, da própria obtenção da Licença Prévia pela mineradora, já que a concessão feita pelo IBAMA foi baseada no EIA questionado.

A esse respeito, faz-se importante destacar que existe ação judicial em trâmite na Justiça Federal, Subsessão Judiciária de Viçosa, autuada sob o número 872-70.2013.4.01.3823, ajuizada em 18 de março de 2013 pela associação civil sem fins lucrativos Instituto Universo Cidadão em face da mineradora Ferrous Resources e IBAMA, na qual se requer

14 Para o primeiro imóvel, o valor indenizatório oferecido pela Ferrous foi de $\mathrm{R} \$ 155.771,65$, sendo alcançado pelo NACAB o valor de R\$322.381,98; para o segundo imóvel, o valor indenizatório oferecido pela Ferrous foi de $\mathrm{R} \$ 97.544,70$, sendo alcançado pelo NACAB o valor de R\$ 264.034,49; e para o terceiro imóvel, o valor indenizatório oferecido pela Ferrous foi de $R \$$ $12.931,19$, sendo alcançado pelo NACAB o valor de $\mathrm{R} \$ 46.108,99$. 
a nulidade da Licença Prévia concedida à empresa, ao argumento justamente da inconsistência dos estudos ambientais que embasaram a sua concessão.

Por fim, o relatório apresentado pela Divisão de Águas e Esgotos da UFV corrobora todas as informações trazidas nos documentos anteriores (AGB e NACAB). O documento pontua que Viçosa é abastecida por dois mananciais superficiais: o ribeirão São Bartolomeu pela Estação de Tratamento 1 (ETA 1) e o rio Turvo Sujo pela ETA 2, sendo que a ETA 1 é responsável por fornecer cerca de $60 \%$ do abastecimento de água do município de Viçosa e $100 \%$ do abastecimento da UFV (DIVISÃO DE ÁGUA E ESGOTO DA UFV, 2012, p. 304).

A partir destas informações, o laudo reafirma que, contrariamente ao que declara a empresa Ferrous, o consumo humano consiste efetivamente no principal uso da água na bacia do ribeirão São Bartolomeu. Ressaltando a fragilidade do sistema do abastecimento de água no município de Viçosa, o estudo reforça a preocupação com os impactos da construção do mineroduto, destacando que:

Trata-se de um manancial de reduzida vazão, desprotegido, com pressões de ocupação urbana e de atividades agropecuárias relativamente intensas na bacia de captação. [...] Trata-se, portanto, de um recurso hídrico vital para Viçosa e a UFV, porém, altamente frágil. Impactos decorrentes de intervenção antrópicas nesse ambiente são magnificados devido às dimensões (reduzidas) do ribeirão São Bartolomeu e dos córregos que o formam (DIVISÃO DE ÁGUA E ESGOTO DA UFV, 2012, p. 313).

Logo, são inconsistentes, conforme o relatório técnico, as informações relativas aos impactos causados nos mananciais do município de Viçosa pela Ferrous, sendo, em muitos momentos, subestimados ou mesmo ignorados pela empresa interessada. Neste sentido, a equipe técnica da Divisão de Água e Esgoto da UFV assevera que as obras do mineroduto, acaso implementadas, provocarão, inevitavelmente, intervenções de vulto no ribeirão São Bartolomeu e em seus córregos afluentes, sendo que os impactos ou não estão 
devidamente identificados ou as medidas mitigadoras propostas pela empresa são impraticáveis ou insuficientes. Posto isto, alerta o documento que:

Mesmo que se tomem 'todas as precauções com utilização das melhores técnicas de engenharia disponíveis', não há como as intervenções previstas serem 'amenas' ou que 'as interferências em áreas localizadas nas proximidades de cursos d'água' sejam 'mínimas', não se sustentam os argumentos de que 'as várias contribuições hidrográficas para a formação dos cursos d'água impede que eventuais impactos nos pontos de interceptação do mineroduto naqueles ribeirões afetem os pontos de captação' e, perante a eventualidade de comprometimento do abastecimento em Viçosa e da UFV, a hipótese de serem adotadas medidas 'alternativas temporárias de abastecimento' é simplesmente impraticável (DIVISÃO DE ÁGUA E ESGOTO DA UFV, 2012, p. 323).

Percebe-se que as considerações e análises técnicas trazidas à apreciação do Ministério Público pelos órgãos acima mencionados parecem agregar valor à racionalidade defendida pelas populações afetadas pelo empreendimento, tornando assim menos assimétrica a disputa de poder travada entre estes e a empresa empreendedora (ZHOURI; ZUCARELLI, 2008). Ao demonstrar cientificamente a existência de fragilidades e incongruências nos estudos ambientais apresentados pela empreendedora, abre-se a possibilidade de questionamento da confiabilidade das análises de impactos até então apresentadas pela empresa, bem como da própria viabilidade da implantação do mineroduto pretendido.

A nosso ver, esta dinâmica foi decisiva para a assinatura de um Termo de Ajustamento de Conduta $^{16}$ (TAC) entre a empresa Ferrous e o

16 O TAC consiste em um documento no qual as partes signatárias se comprometem perante o Ministério Público a cumprirem determinadas condições, de forma a resolverem extrajudicialmente um conflito. Uma vez formalizado, o TAC possui valor de título executivo extrajudicial, podendo ser levado a juízo para execução forçada, no caso de seu descumprimento. 
Ministério Público do Estado de Minas Gerais. O documento, acostado às páginas 340 a 343 do Inquérito Civil MPMG n 0713.12.000149-8, estabelece como cláusula principal a suspensão de todas as atividades de implantação do mineroduto nas áreas de entorno do Ribeirão São Bartolomeu, Rio Turvo Sujo e Rio Turvo Limpo (mananciais do município de Viçosa), ressalvada a apresentação de novos estudos técnicos a respeito do abastecimento de água na cidade de Viçosa a serem trazidos para análise com antecedência mínima de 8 meses.

Importante ressaltar que, pela leitura do TAC celebrado, percebese que o documento limitou-se ao tratamento das questões referentes ao abastecimento de água no município de Viçosa, não sendo abordadas as questões "sociais" apontadas tanto pelos representantes dos movimentos sociais quanto nos estudos técnicos que contestaram o EIA da empresa Ferrous. Isto porque, conforme se asseverou anteriormente, as implicações "sociais" do mineroduto foram encaminhadas à $4^{\text {a }}$ Promotoria de Justiça de Viçosa. Desta feita, no presente Inquérito Civil não se tem notícia das medidas adotadas em relação aos demais aspectos do mineroduto pela $4^{\text {a }}$ Promotoria de Justiça, notadamente as questões fundiárias.

Com a assinatura do TAC em 05 de abril de 2013, a $2^{\text {a }}$ Promotoria de Justiça se pronunciou pelo arquivamento dos autos do Inquérito Civil, por entender que, não havendo notícia de novas intervenções ambientais por parte da empresa mineradora, desnecessária se faria a manutenção do procedimento (INQUÉRITO CIVIL MPMG no 0713.12.000149-8, 2012, p. 349). O arquivamento ocorreu em 10 de maio de 2013. Porém, remetidos os autos do procedimento ao Conselho Superior do Ministério Público para análise da promoção de arquivamento ${ }^{17}$, o mesmo não foi homologado. Em sua apreciação do arquivamento proposto pela $2^{a}$ Promotoria de Justiça de Viçosa, o Conselho Superior deliberou pelo

17 O arquivamento dos Inquéritos Civis instaurados no âmbito do Ministério Público do Estado de Minas Gerais, para sua validade, deve ser necessariamente homologado pelo Conselho Superior do Ministério Público, órgão colegiado composto por Procuradores de Justiça sediado em Belo Horizonte/MG. 
prosseguimento do feito, com seu consequente retorno à Promotoria de origem para acompanhamento e apuração do integral cumprimento do TAC celebrado (INQUÉRITO CIVIL MPMG no 0713.12.000149-8, 2012, p. 358).

\section{Conclusão}

Descortinou-se nos autos do Inquérito Civil MPMG $\mathrm{n}^{0}$ 0713.12.000149-8 instaurado pela $2^{\mathrm{a}}$ Promotoria de Justiça de Viçosa a dinâmica de um conflito ambiental de amplas proporções. Isto porque, para além dos interesses das populações locais das áreas de passagem do mineroduto da Ferrous Resources no município de Viçosa (o que, por si só, já caracteriza impactos preocupantes e significativos), o próprio abastecimento de água em toda a cidade pode vir a ser inviabilizado caso o mineroduto seja efetivamente construído, o que afetaria diretamente um universo de quase 77 mil pessoas ${ }^{18}$.

Percebe-se, na verdade, uma disputa entre duas racionalidades distintas: de um lado, o interesse econômico da empresa no mineroduto, e, de outro, os modos de vida tradicionais das populações locais do entorno do mineroduto, assim como a garantia de acesso aos recursos hídricos, haja vista o potencial comprometimento dos mananciais do município.

Neste sentido, se, de um lado, se trata de verdadeiro confronto entre diferentes atores sociais pelo acesso e formas de uso do território e de seus recursos naturais; por outro, é também uma luta simbólica, um conflito de discursos, no qual cada um dos lados busca legitimar a sua racionalidade a partir de seu próprio campo de valores.

A celebração do TAC, muito embora não tenha contemplado as questões "sociais" do empreendimento, possibilitou a suspensão das

\footnotetext{
18 População estimada do município de Viçosa para o ano de 2014 segundo dados do Instituto Brasileiro de Geografia e Estatística (IBGE), informação constante em: <http://cidades.ibge.gov. $\mathrm{br} / \mathrm{xtras} /$ perfil.php?codmun=317130>.
} 
obras, condicionando-a a apresentação de estudos ambientais mais consistentes caso a mineradora insista no seu interesse de implantação do mineroduto, o que parece sinalizar o êxito no empoderamento dos segmentos sociais contrários à construção.

Logo, se é possível concluir que o conflito originado pela implantação do empreendimento em questão aponta para uma situação de injustiça ambiental, dada a aparente assimetria de condições entre empreendedora e populações afetadas, certo é que a atuação da assessoria prestada por organizações civis contribuiu para a redução dessa desigualdade. Contudo, uma preocupação é que, diante da mobilização social ocorrida no município de Viçosa, as consequências ambientais do empreendimento possam ser transferidas para outras áreas de menor organização política e resistência social.

Fato é que, para além das questões pontuais, o conflito ambiental analisado evidencia as próprias contradições de um modelo de desenvolvimento capitalista, no qual empreendimentos da mesma natureza que o mineroduto da empresa Ferrous Resources são tidos como indispensáveis ao progresso do país e, portanto, legitimados em detrimento de outros modos tradicionais de apropriação do território e de seus recursos naturais. Portanto, o debate a respeito da legitimidade desta racionalidade, que reduz ou desconsidera as reais implicações dos impactos ambientais advindos de tais empreendimentos é, em última instância, o debate a respeito das próprias escolhas do chamado "desenvolvimento".

\section{Referências}

ACSELRAD, Henri. As práticas espaciais e o campo dos conflitos ambientais. In: ACSELRAD, Henri (Org.). Conflitos ambientais no Brasil. Rio de Janeiro: Relume-Dumará, 2004a. p. 23-35.

ACSELRAD, Henri. Conflitos ambientais - a atualidade do objeto. In: Conflitos ambientais no Brasil. Rio de Janeiro: Relume-Dumará, 2004a. p. 7-11. 
ACSERALD, Henri. Justiça ambiental: ação coletiva e estratégias argumentativas. In: ACSELRAD, Henri et al. (Org.). Justiça ambiental e cidadania. Rio de Janeiro: Relume Dumará, 2004b. p. 23-39.

ACSELRAD, Henri; HERCULANO, Selene; PÁDUA, José Augusto. A justiça ambiental e a dinâmica das lutas socioambientais no Brasil uma introdução. In: ACSELRAD, Henri et al. (Org.). Justiça ambiental e cidadania. Rio de Janeiro: Relume Dumará, 2004b. p. 08-20.

ALONSO, Ângela; COSTA, Valeriano. Por uma sociologia dos conflitos ambientais no Brasil. In: ALIMONDA, H. (Ed.). Ecología política, naturaleza, sociedad y utopía. Buenos Aires: CLACSO. 2002. p. 115137.

ANDRADE, José Célio Silveira; RIBEIRO, Maria Teresa Franco et al. Conflitos Sócio-Ambientais: análise da relação entre o complexo Costa do Sauípe e atores locais. Disponível em: <http://www.anppas. org.br/encontro_anual/encontro1/gt/dimensoes_socio_politicas/ Jose\%20Celio\%20Silveira\%20Andrade.pdf>. Acesso em: 25 ago. 2016.

ASSOCIAÇÃO DE GEÓGRAFOS DO BRASIL. AGB Seção Viçosa. Relatório sobre os impactos socioambientais do Mineroduto da Ferrous Resources, na microrregião de Viçosa/MG. Inquérito Civil MPMG 0713.12.000149-8. Viçosa, 2012.

BRASIL. Ministério Público do Estado de Minas Gerais. Inquérito Civil MPMG n0713.12.000149-8. Descrição do fato: Apurar denúncias a respeito de degradação ambiental causada pela implantação do mineroduto da Ferrous Resources do Brasil no município de Viçosa. Representado: Ferrous Resources do Brasil. Viçosa, 2012.

CASTELLS, Manuel. A sociedade em rede. São Paulo: Paz e Terra, 1999.

CENTRAL DE APOIO TÉCNICO DO MINISTÉRIO PÚBLICO DO ESTADO DE MINAS GERAIS - CEAT. Laudo Técnico. Inquérito Civil MPMG n0713.12.000149-8. Belo Horizonte, 2012. 
DI PIETRO, Maria Sylvia Zanella. Direito administrativo. 18. ed. São Paulo: Atlas, 2008.

GOULD, Kenneth. Classe social, justiça ambiental e conflito político. In: ACSELRAD, Henri et al. (Org.). Justiça ambiental e cidadania. Rio de Janeiro: Relume Dumará, 2004. p. 69-80.

LITTLE, Paul Elliott. Os conflitos socioambientais: um campo de estudo e de ação política. In: BURSZTYN, Marcel. A difícil sustentabilidade. Rio de Janeiro: Garamond, 2001. p. 107-122.

NÚCLEO DE ASSESSORIA ÀS COMUNIDADES ATINGIDAS POR BARRAGENS. NACAB. Manifestação sobre o EIA/RIMA do Mineroduto da Ferrous Resources do Brasil. Inquérito Civil MPMG n 0713.12.000149-8. Viçosa, 2012.

OLIVEIRA, Sônia. A releitura dos critérios de justiça na região dos Lagos do Rio de Janeiro. In: ACSELRAD, H. (Org.). Conflitos ambientais no Brasil. Rio de Janeiro: Relume-Dumará, 2004. p. 95130.

ROTHMAN, Franklin Daniel. Vidas alagadas: conflitos socioambientais, licenciamentos e barragens. Viçosa: UFV, 2008. p. 19-32.

SERVIÇO AUTÔNOMO DE ÁGUA E ESGOTO. SAAE. Relatório Técnico. Inquérito Civil MPMG nº 0713.12.000149-8. Viçosa, 2012.

SOUSA, Dayane Rouse Neves; OLIVEIRA, Marcelo Leles Romarco; FONSECA, Bruno Costa. Conflitos na implantação do Mineroduto da Ferrous: a percepção dos atores sociais sob suas causas e desdobramentos. RDG Revista do Departamento de Geografia da USP, São Paulo, v. 25, p 140-163, 2013.

UNIVERSIDADE FEDERAL DE VIÇOSA. DIVISÃO DE ÁGUAS E ESGOTO. Implantação do Mineroduto da Ferrous Resources na Bacia do Ribeirão São Bartolomeu: Impactos sobre o Abastecimento de Água em Viçosa - MG. Parecer Técnico. Inquérito Civil MPMG nº 0713.12.000149-8. Viçosa, 2012. 
VARGAS, Glória Maria. Conflitos sociais e sócio-ambientais: proposta de um marco teórico e metodológico. Sociedade e Natureza, Uberlândia, n. 19, p. 191-203, $2^{\circ}$ semestre de 2007.

ZHOURI, Andrea; LASCHEFSKI, Klemens; PAIVA, Ângela. Uma sociologia do licenciamento ambiental: o caso das hidrelétricas em Minas Gerais. In: ZHOURI, Andréa et al. (Org.). A insustentável leveza da política ambiental: desenvolvimento e conflitos socioambientais. Belo Horizonte: Autêntica, 2005.

ZHOURI, Andrea; ROTHMAN, Franklin Daniel. Assessoria aos atingidos por barragens em Minas Gerais: desafios, limites e potenciais. In: ROTHMAN, Franklin Daniel (Org.). Vidas alagadas: conflitos socioambientais, licenciamentos e barragens. Viçosa: UFV, 2008. p. 122-168.

ZHOURI, Andréa; ZUCARELLI, Marcos Cristiano. Mapa dos conflitos ambientais no Estado de Minas Gerais: notas preliminares de uma pesquisa em andamento. In: ENCONTRO NACIONAL DA ANPPAS, IV., 04 a 06 de junho de 2008. Brasília. Anais... Brasília, DF, 2008. Disponível em: <http://www.anppas.org.br/encontro4/cd/ARQUIVOS/ GT6-753-429-20080511203621.pdf>. Acesso em: 5 abr. 2016

ZHOURI, Andréa; LASCHEFSKI, Klemes (Org.). Desenvolvimento e conflitos ambientais. Belo Horizonte: UFMG, 2010. v. 1.

Recebido em: 26/08/2015

Aprovado em: 11/12/2015 